\title{
Muon g-2 Experiments
}

DOI: $10.3938 /$ PhiT.24.033
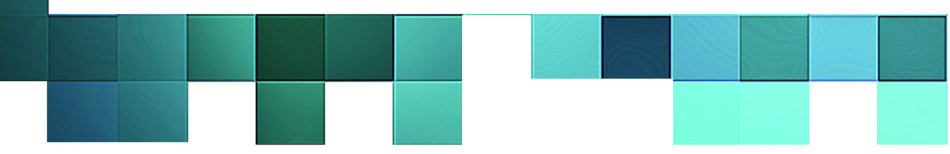

\section{김 영 임}

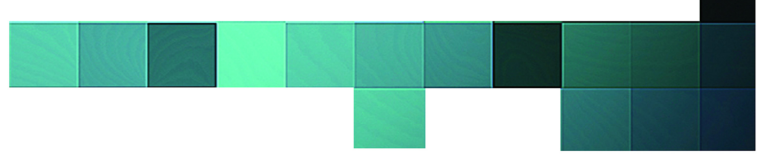

\section{Muon g-2 Experiments}

\section{Young-Im KIM}

The measurements of the muon's anomalous magnetic moment with high precision are very important to check the possibilities of physics beyond the Standard Model (SM). Presently, the measured value from an experiment held at Brookhaven National Laboratory is different from the theoretically-expected value based on the SM physics by about 3.5 standard deviations. There are two proposed muon g-2 experiments in the world, one in Japan and the other in USA. The Center for Axion and Precision Physics Research (CAPP) of the Institute for Basic Science are working on a new muon g-2 experiment, which aims to obtain a precision better than that in previous experiments. In this article, the physics motivation, the principle of the muon g-2 experiments and the CAPP/IBS contributions will be presented.

뮤온의 비정상 자기 모멘트(anomalous magnetic moment)의 정밀 측정은 입자물리학의 표준 모형을 넘어서는 새로운 물리학 의 가능성을 찾는 데에 매우 중요하다. 이에 대해 일본과 미국에 서 각각 국제 공동 연구가 진행 중이며, 기초과학 연구원 액시온 및 극한 상호작용 연구단도 이에 참여 중이다. 이 실험들은 이전 뮤온 비정상 자기 모멘트 측정 실험에 비해 높은 정밀도로 측정 하는 것을 목표로 하고 있다. 이 글에서는 이 실험의 물리학적 이론, 실험 원리, 본 연구단의 활동에 대해 논하였다.

입자물리학의 표준 모형은 원자 이하의 입자들에 대한 전자 기 상호작용, 약한/강한 상호작용에 대한 이론이며, 흔히 "거의

\section{저자약력}

김영임 박사는 경북대학교 이학박사로서(2012), University of Oxford에 서 Postdoc(2012-2014)을 거쳐 현재 IBS 액시온 및 극한상호작용연구 단(CAPP) 연구위원으로 재직 중이다. (youngim@ibs.re.kr)
모든 것의 이론”이라고 불리워진다. 그러나 표준모형이 자연 현 상을 모두 기술하는 데에는 부족함이 있다는 것에 대한 많은 논의가 있으며, 뮤온의 비정상 자기 모멘트도 그 중 하나이다.

양자역학이 발전함에 따라 아원자 입자들의 자기 모멘트에 대 한 연구도 발전하였다. 페르미온의 경우 자기 쌍극자 모멘트는 스핀과 관련이 있다. 디랙의 상대론적 양자역학 이론 ${ }^{[1]}$ 의 가장 큰 성과는 이른바 $\mathrm{g}$ 인자를 예측한 데 있다. 이에 따르면 $\mathrm{g}$ 인 자는 자기 모멘트와 자기 회전 비율(gyromagnetic ratio) 사이의 비율로 정의되는데, 이 값은 2 로 예측된다. 전자의 경우 $\mathrm{g}$ 인자 는 2 이고, 디랙의 이론이 자연을 잘 설명하는 것처럼 보였다. 이후 예상치 못한 연구결과가 발표되었는데, 1933년, 양성자의 $\mathrm{g}$ 인자가 2가 아닌, 5.586으로 측정되었다. 1940년에 Alvarez 와 $\mathrm{Bloch}^{[2]}$ 는 중성자의 $\mathrm{g}$ 인자도 큰 값을 가짐을 발견하였다.

뮤온은 1933년에 처음 발견되었다. 뮤온은 경입자의 일종으 로, 전자보다 207배 무겁다. 뮤온도 전자와 같이 양자전기역학 을 따르며, 다른 입자와 전자기력과 약력을 통해 상호작용한다. 전자와 다른 점은, 안정하지 않고 붕괴하는 입자라는 것인데, 대 부분 약한 상호작용인 $\mu^{-} \rightarrow e^{-} \nu_{\mu} \nu_{e}$ 반응을 통해 붕괴한다. 뮤온 의 반감기는 $2.2 \mu \mathrm{s}$ 로 긴 값을 가지는데, 이를 통해 뮤온의 질 량, 반감기, 자기 모멘트 등을 정밀 측정하는 것이 가능하다. 뮤 온의 g 인자는 전자와는 조금 달라서, 전자기 상호작용과 그를 통해 예측되는 자기 쌍극자 모멘트만으로는 설명되지 않는다.

이론적으로는, 뮤온의 g 인자는 표준 모형이 아닌 다른 물리 학 이론에 의해 영향 받을 수 있기 때문에, 정밀한 측정 시도 가 이루어져 왔다. 미국 브룩헤이븐 국립 연구소에서의 E821 실험의 최종 결과가 2006년 11월에 나왔는데, 이에 의하면 뮤 온의 g 인자는 2.0023318416(13)로 측정되었다. ${ }^{[3]}$ 이를 표준 모형에서 계산된 이론적 예측치 2.0023318361(10)와 비교하

\section{REFERENCES}

[1] P.A.M. Dirac, Proc. R. Soc. (London) A 117, 610 (1928), and A 118 , 351 (1928). See also, P.A.M. Dirac, The Principles of Quantum Mechanics, 4th edition (Oxford University Press, London, 1958).

[2] Luis W. Alvarez and F. Bloch, Phys. Rev. 57, 111 (1940).

[3] Muon (g-2) Collaboration, G. W. Bennett et al., Phys. Rev. D 73072003 (2006). 


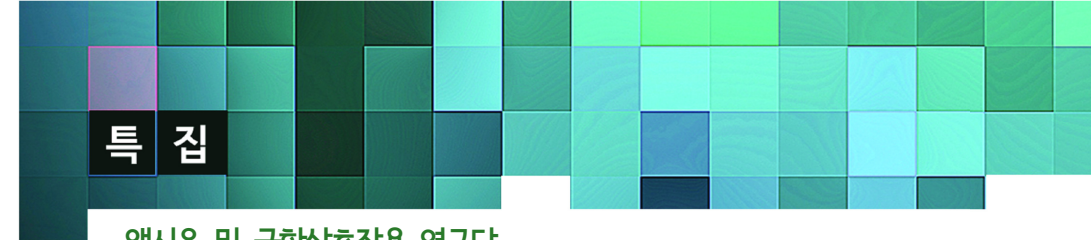

액시온 및 극한상호작용 연구단

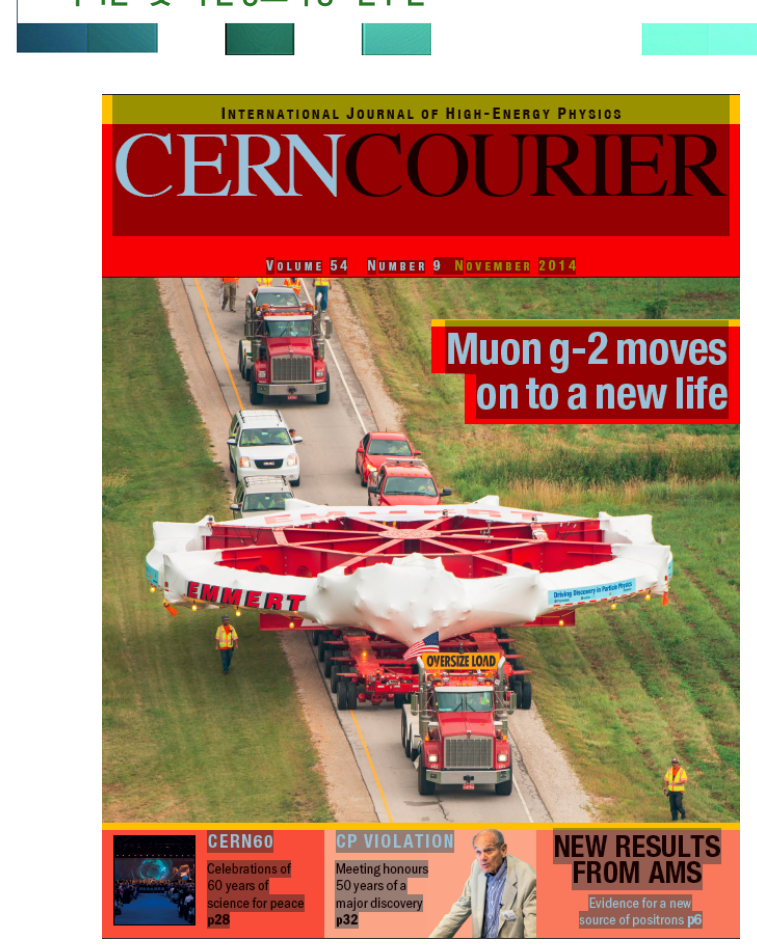

Fig. 1. The storage ring has been moved successfully last year, from Brookhaven National Laboratory to Fermilab for the new muon g-2 experiment.

면 오차의 합보다 약 3-4배 차이가 나며, 이 차이는 중입자의 영향을 이론적 예측에 어떻게 적용하느냐에 따라 차이가 난 다. ${ }^{[4]}$ 이러한 3-4배의 차이는, 흔히 새로운 발견으로써 인정되 는 오차의 5 배 이상 차이보다는 작은 것이다. 이 실험 결과가 실제적으로 큰 차이를 보여주는 것인지, 궁극적으로 표준모형 과 일치함을 말해주는 것인지에 따라, 새로운 물리이론에 대한 제한조건을 주게 될 것이다.

브룩헤이븐 연구소에서의 실험결과를 확증 혹은 반증하는 목 적으로 새로운 뮤온 비정상 자기 모멘트의 정밀 측정 실험이 미국과 일본에서 독립적으로 제안되었다. 미국에서의 실험 제안 은 페르미 국립 가속기 연구소에서 진행될 것이며 (E989), 측정 의 정밀도를 4 배 증가시키는 것을 목표로, 브룩헤이븐 연구소에 서 사용했던 저장링 자석과 관련 시설을 재사용하기로 하였 다. ${ }^{[4]}$ 일본 J-PARC에서의 실험 제안은 완전히 새로운 개념의 실험을 제안한 것인데 목표로 하는 정밀도는 $\mathrm{E} 989$ 과 비슷하다.

이 실험에서는 뮤온은 편극화되어 저장링에 입사되고, 스핀 의 변화를 측정함으로써 $\mathrm{g}$ 인자를 얻어낸다. $\mathrm{g}$ 인자가 정확히 2 이라면, 뮤온의 스핀은 운동량 방향으로 지속될 것이다. 2 보 다 크다면 스핀은 세차운동을 하게 되는데, 그 크기는 비정상 자기 모멘트에 비례한다.

이 실험에서는 계통 오차를 줄이는 것이 궁극적인 목표이다. 이를 위해서는 더 많은 뮤온 입자가 필요한데, 페르미 연구소 E989 실험에서는 거의 $100 \%$ 편극화된 순수하고 강한 뮤온빔

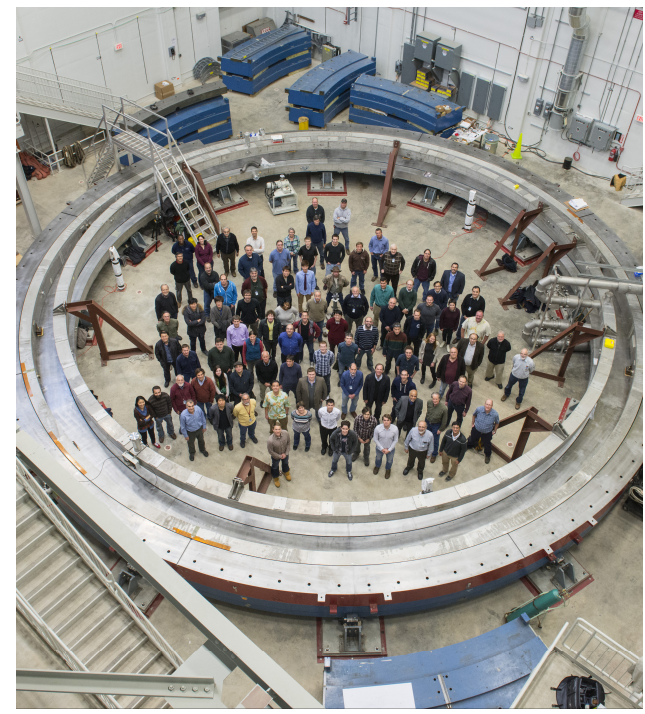

Fig. 2. Re-assembly of the g-2 storage-ring magnet at Fermilab was positioned gently on top of the newly assembled bottom ring of steel yoke segments. The coils and their complex interconnect system (top right in photo) were transported as a single unit from Brookhaven to Fermilab by land, sea and river, in 2013. This photo was taken during the collaboration meeting at 2014. Image credit: Fermilab.

을 저장링에 입사한다. 저장링과 부대시설은 재사용하는 것들 이지만 실제로는 거의 새 실험과 같다. 빔의 강도가 더 높고, 입사율이 더 높고, 계통 오차를 줄이는 것이 중요하기 때문에 이 실험을 위해 많은 장치들의 성능이 개선되어야 하기 때문이 다. 이 저장링과 장치들을 브룩헤이븐 연구소에서 페르미 연구 소로 옮기는 것은 매우 어려운 작업이었으나 이미 성공적으로 완료되었다 (그림 1,2).

그림 3은 저장링과 그에 포함된 inflector, kicker (K1 - K3), 사극자석(Q1-4)의 배치를 보여주고 있다. 빔의 진향방향으로 편극된 뮤온은 초전도 저장링에 입사된다. 초전도 inflector는 주 자석에 존재하는 자기장을 제거하는데 사용되는데, 이를 통 해 빔이 저장링 안에 가능한한 짧은 경로로 들어올 수 있게 한 다. 뮤온을 저장링 안에 정확한 궤적으로 입사시키기 위해 kicker를 사용한다. 사극전자석은 뮤온의 수직방향 궤적을 안 정시키기 위해 사용한다. 뮤온 스핀의 운동은 이러한 집속 전 자기장에 의해 영향 받는데, 수직방향 전기장과 자기장이 각각 독립적으로 스핀의 세차 주파수에 영향을 준다. 이른바 magic gamma를 사용함으로써 전기장에 의한 스핀 세차를 제거한다. 이 magic gamma는 29.3이며, 이는 뮤온 운동량 $3.09 \mathrm{GeV} / \mathrm{c}$ 에 해당하고, 이때 뮤온의 반감기는 $64.4 \mu \mathrm{s}$ 이 된다.

일본 J-PARC의 뮤온 비정상 자기 모멘트 및 전기 모멘트

\section{REFERENCES}

[4] T. Blum et al., 2013 arXiv:1311.2198. 

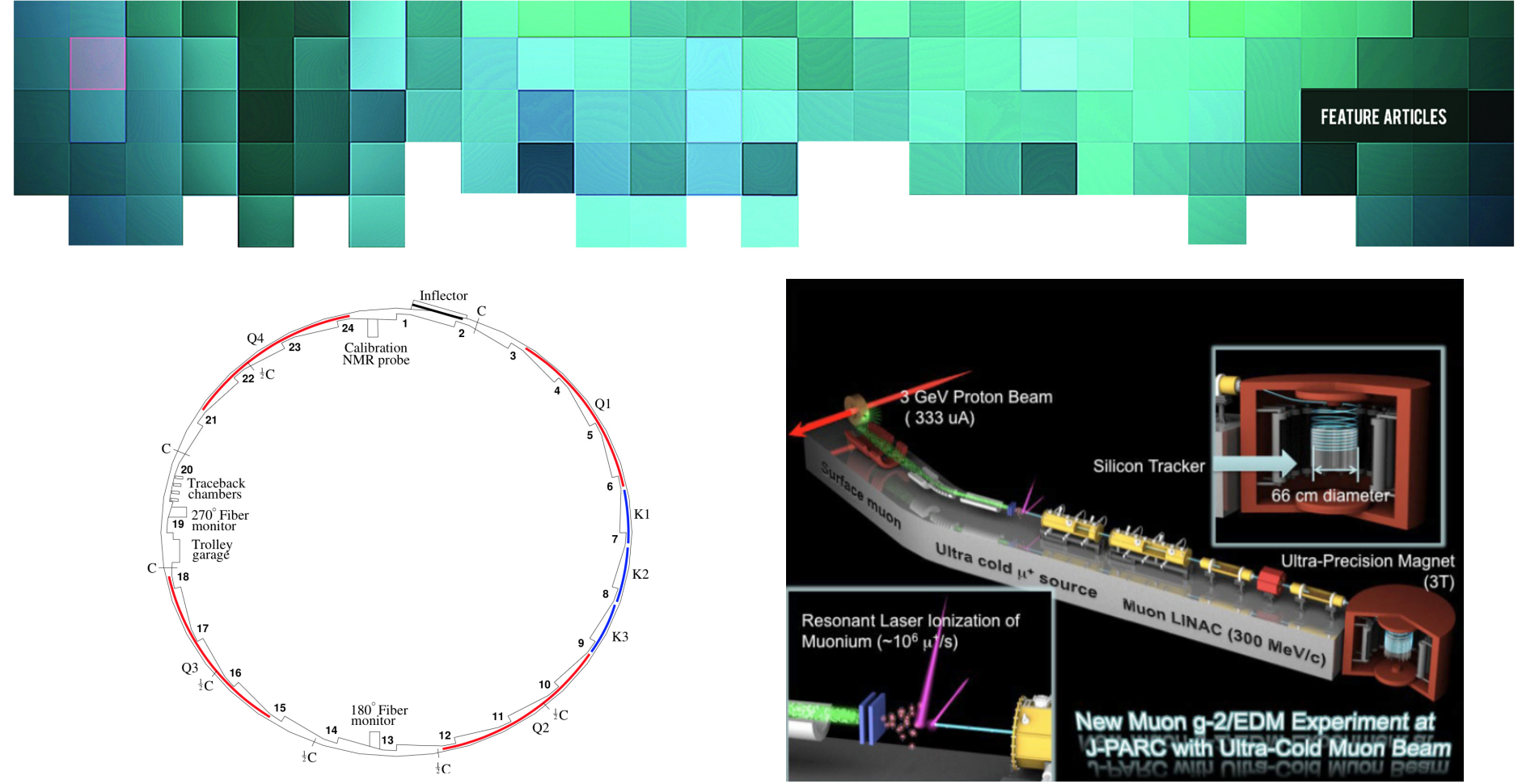

Fig. 3. The layout of the storage ring, as seen from above, showing the location of the inflector, the kicker sections (labeled K1-K3), and the quadrupoles (labeled Q1-Q4).

측정 실험의 실험 방식은 이전의 실험과는 매우 다르다. 이전 실험에서는 $3.1 \mathrm{GeV}$ 에너지의 뮤온과 14 미터 지름의 저장링 을 사용했으며, 뮤온 붕괴 후 방출되는 양전자를 측정하기 위 한 열량계를 사용하였으나, J-PARC에서의 실험은 뮤온의 에너 지가 훨씬 작으며, 저장링의 크기도 역시 작다. 이전 실험에서 의 뮤온의 에너지는 집속 전기장에 의한 스핀 세차를 제거하기 위하여 선택되었는데, J-PARC에서의 실험은 매우 작은 에너지 의 뮤온을 사용하기 때문에 빔의 집속에 필요한 전기장의 크기 도 작다. 그러므로 약 $300 \mathrm{MeV} / \mathrm{c}$ 의 뮤온 운동량을 사용하고, $3 \mathrm{~T}$ 자기장의 MRI와 비슷한 솔레노이드를 사용한다.

작은 에너지의 뮤온 빔을 사용함으로써 뮤은 스핀의 반전이 더 자주 발생할 수 있다. 이는 이벤트의 겹침(file-up)과 같이 검출기 효율에 영향을 주는 계통 오차를 제거하는데 사용된다. 스핀 반전은 페르미연구소의 실험에서는 발생하지 않으며 이전 의 실험에서도 사용되지 않았다. 스핀 반전은 또한 전기 모멘 트의 측정에서 계통 오차를 줄이는 데에도 유용하게 사용된다.

뮤온 손실과 뮤온의 간섭 베타트론 진동(coherent betatron oscillation, $\mathrm{CBO}$ )은 페르미 연구소 실험에서 계통 오차를 줄이 는데에 매우 중요한 이슈이다. 이를 제거하기 위해 라디오파 대역의 전기장을 사극 전자석(그림 5) 위/아래와 좌우에 10 $\mathrm{kV}$ 를 인가하여 만들고, 이를 이용하여 저장링 안에서의 뮤온 빔의 위상과 적절히 일치시킨다. 본 연구단은 이와 같은 아이 디어를 제안하였고 실제 실험에 적용하기 위한 연구를 진행 중 이다. 만약 이 아이디어가 성공적이라면 이전 실험에서의 계통 오차의 주된 이유인 두 가지, 뮤온 손실과 뮤온의 간섭 베타트 론을 상당히 줄일 것이다.

빔의 입사과정에서 사용되는 kicker는 새로 제작/설치될 예

Fig. 4. Conceptual representation of the muon g-2/EDM experiment at J-PARC MLF.

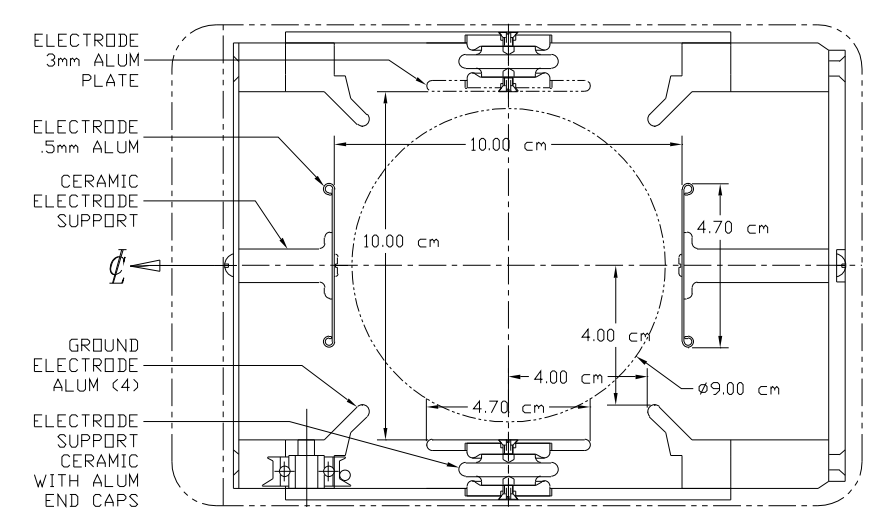

ELECTRTDE AND SUPPQRT FRANE - END VIE

Fig. 5. A schematic of the quadrupole cross section.

정인데, 이때 kicker의 자기장 변화에 의해 생성되는 와전류가 저장링의 자기장에 영향을 끼칠 가능성이 있다. 이 와전류에 의해 생성되는 잔류 자기장이 충분히 크면 뮤온 스핀 세차운동 에 영향을 끼치게 된다. 본 연구단은 와전류에 의한 잔류 자기 장의 측정 방법에 대한 연구를 진행 중이다. 레이저가 유전체 를 통과할 때 편극 벡터 회전율이 자기장의 존재 하에서는 바 뀐다는 패러데이 효과를 이용하여, kicker의 와전류와 잔류 자 기장이 측정될 수 있다.

이제까지 두 개의 다른 뮤온 비정상 자기 모멘트 측정 실험 에 대해 간략히 설명하였다. 두 실험은 2016/2017년에 데이 터 수집을 시작할 계획이며, 향후 5년간 이 두 실험이 성공적 으로 운영되는 것은 물리학적인 관점에서 매우 중요하다. 본 연구단은 이 두 실험 모두에서 중요한 역할을 수행할 계획이며 이를 통해 표준 모형의 수정과 새로운 물리의 가능성에 대해 기여할 수 있을 것이다. 